\title{
CONTRIBUTION TO ESTIMATING BEARING CAPACITY OF PILE IN CLAYEY SOILS
}

\author{
Marián DRUSA ${ }^{1 *}$, Filip GAGO ${ }^{1}$, Jozef VLČEK ${ }^{1}$ \\ ${ }^{1}$ Department of Geotechnics, Faculty of Civil Engineering, University of Žilina, Univerzitná 8215/1, \\ 01026 Žilina, Slovakia. \\ corresponding author: drusa@fstav.uniza.sk.
}

\section{Abstract}

The estimation of real geotechnical parameters is key factor for safe and economic design of geotechnical structures. One of these are pile foundations, which require proper design and evaluation due to accessing more deep foundation soil and because remediation work of not bearable piles or broken piles is a crucial operation. For this reason, geotechnical field testing like cone penetration test (CPT), standard penetration (SPT) or dynamic penetration test (DP) are realized in order to receive continuous information about soil strata. Comparing with rotary core drilling type of survey with sampling, these methods are more progressive. From engineering geologist point of view, it is more important to know geological characterization of locality but geotechnical engineers have more interest above the real geotechnical parameters of foundation soils. The role of engineering geologist cannot be underestimated because important geological processes in origin or during history can explain behaviour of a geological environment. In effort to streamline the survey, investigation by penetration tests is done as it is able to provide enough information for designers. This paper deals with actual trends in pile foundation design; because there are no new standards and usable standards are very old. Estimation of the bearing capacity of a single pile can be demonstrated on the example of determination of the cone factor $N_{k}$ from CPT testing. Then results were compared with other common methods.
\end{abstract}

\section{Keywords:}

Pile foundation;

Cone penetration testing;

Load capacity;

Total cohesion of soil;

Neogenous sediments.

\section{Introduction}

One of the basic prerequisites for an economically efficient and safe design of a foundation structure is the determination of appropriate and reliable geotechnical parameters of the geological environment, in which the proposed structure will operate. In-situ geotechnical testing is the preferred method to determine the continuous values of geological environment and a suitable method should be selected according to layer compositions, its origin and past processes in history $[1,2]$. The current situation in geological survey works has a tendency in reducing cost and time of field works and laboratory analyses. Generally, it can be seen that the trend of not using sufficient laboratory sample analysis is mainly due to time demanding processes and higher costs, [2]. This trend is not convenient in order to ensure the stability and reliability of designed structures during lifetime and its geological surrounding. This "pressure" to engineering geologists may lead to underestimation of poorly deep-laid layers, absence of important properties or not confirming the real behaviour of important soils and rocks [3, 4].

From a geotechnical point of view, cone penetration test (CPT) is one of the most efficient tests, which creates a near perfect image from geological environment. This method of in-situ testing can derive the strength and deformation characteristics, is able to identify geological layers' strata, can fixed index properties of soils such as relative density, and consistency. Nowadays, direct interpretation of soils type by CPT tests and other classifications are used [5]. This can lead to a lot of discussion about precision of classification of soil type in this case.

On the other hand, there is the question of what is more important in terms of future use of CPT soundings - derived data or classification of penetrated layers. This can be proved by purpose of testing. This article focuses on deriving parameters that lead to an estimation of pile load capacity in 
fine soil sediments - like neogenous clays, silts, sandy clays, and sandy silts. When identification of soil type is more important, it is highly recommended in geotechnical practice to drill boreholes situated closed to every CPT probe to be precise in further interpretation of soil profile, [5].

The cone penetration test is simple technology, which measures the resistance of the tip (cone resistance) and friction on mantel (local skin friction after cone). Nowadays, there can be used mechanical cone $(\mathrm{CPTm})$, piezocone $(\mathrm{CPTu})$, seismic piezocone $(\mathrm{sCPTu})$, and resistivity cone RCPTu. Following Figure 1 shows results obtained by mechanical cone type Begemann (left) and electrical piezocone (right).
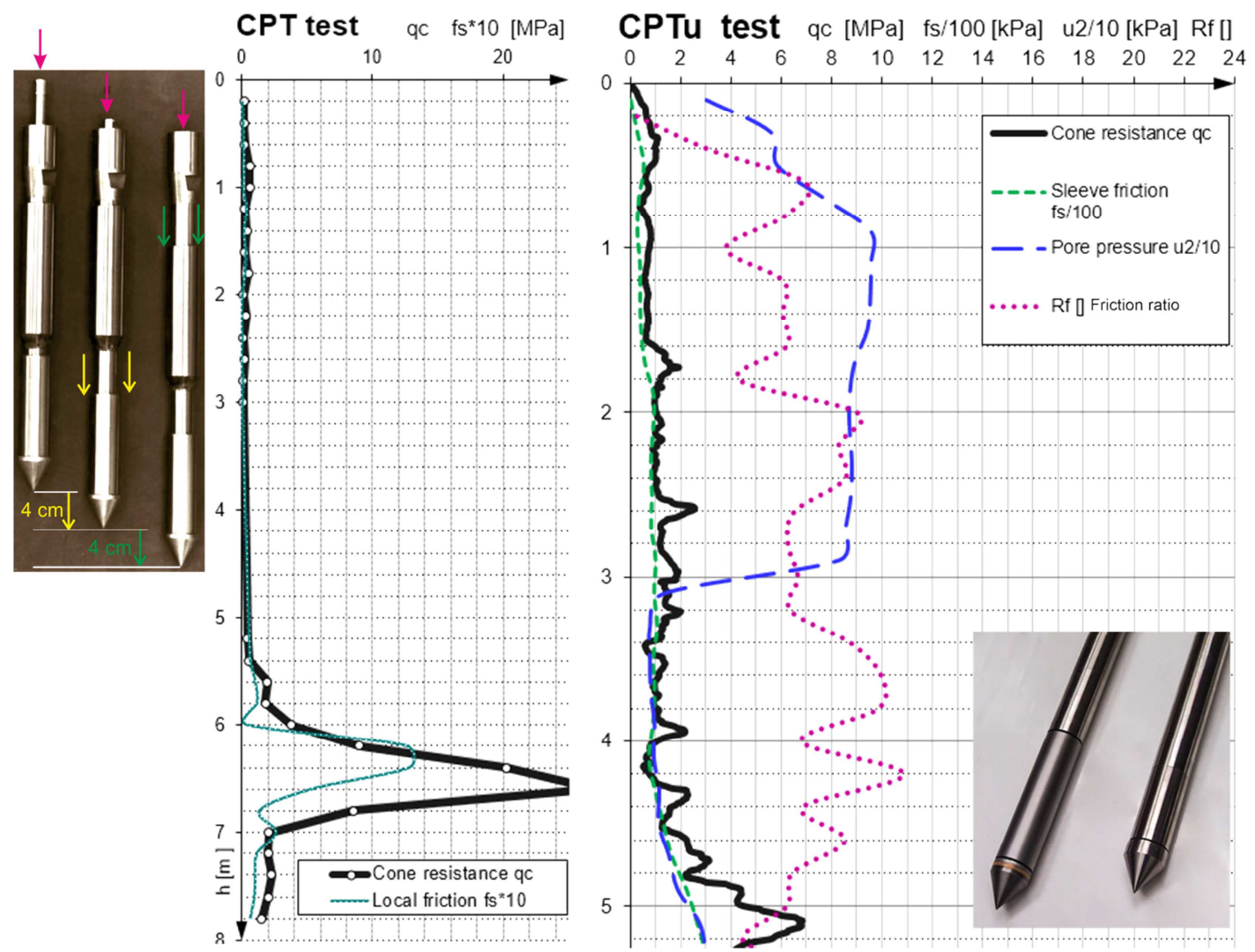

Fig. 1: Cone penetration testing CPTm (left) and CPTu (right).

The main difference between using mechanical and electrical cones is in sensitivity of received data. Mechanical cone measures every $20 \mathrm{~cm}$ interval in three partial steps of cone penetration, $4 \mathrm{~cm}$ of each and rest of depth interval $12 \mathrm{~cm}$ is not measured. Electrical piezocone works continuously thanks to sensors and data acquisition operates automatically every $1 \mathrm{~cm}$ depth interval. Time of testing is also interesting when deeper probes are realized; it can be finished in half the time according to tests with mechanical cones.

\section{Application of CPT testing for design of pile foundation}

Pile load capacity (maximum compressive resistance) in the case of bored piles contains base resistance (at bottom) $F_{\max }$, base and shaft resistance $F_{\max }$, shaft. In many cases, shaft resistance is not considered when stiffness and shear strength of soil is very low, recommended value for neglecting is with average cone resistance $q_{c}$ less than $2 \mathrm{MPa}$. From Eurocode 7, calculation of bearing capacity of a single pile is recommended from eq. (1), [6]:

$F_{\max }=F_{\max , \text { base }}+F_{\max , \text { shaft }}=A_{\text {base }} \cdot p_{\text {max }, \text { base }}+\int_{0}^{\Delta L} O_{p} \cdot p_{\max , \text { shaft }} \cdot d z$

where: $A_{\text {base }}\left[\mathrm{m}^{2}\right]$ - is cross section area of pile at bottom, $O_{p}[\mathrm{~m}]$ - is the circumference of pile shaft where base of pile is placed, $\Delta L[\mathrm{~m}]$ - is the distance from the base of pile to bottom of first weak 
unbearable soil layer $\left(q_{c} \leq 2 \mathrm{MPa}\right)$, and $z[\mathrm{~m}]$ - is the depth or vertical direction positive from top to bottom of pile.

In the following step $p_{\text {max,base }}$ can be derived from cone penetration resistance curve based on three parts with average values of resistance $q_{c, \text { I,mean }}, q_{c, \text { II,mean, }} q_{c, \text { III, mean }}$. The difficulties arise here with estimation of mean values, therefore other methods for calculation of bearing capacity of single pile from CPT testing should be recommended. Article presents direct and indirect calculation of bearing capacity, which was used in the model locality with neogenous fine clay sediments.

At the first look, cone penetration testing is a direct simulation of statically installed micropiles, where bearing capacity at base of pile is measured by cone, and sleeve friction measurements represent shaft resistance of pile. The principle of conventional soil mechanics can be applied for the analysis of pile foundations; it means indirect use of CPT testing data, where it is necessary to know the parameters $s_{u}, K_{0}, \varphi^{\prime}$, and $\alpha$ and $\beta$ or by direct CPT assessments, where measured values are proportional to the load values acting on the piles, [8].

The emphasis in this article is the vertical load capacity of pile (tensile, compressive), but in the practice cannot be neglected either the horizontal components of the reactions or the effect of bending moments. For tension analysis, only the skin friction can be taken into account. For tension loads applied in undrained stress conditions, the shaft friction resistance is in level 70 - $90 \%$ comparing with resistance acting on pressure [9].

\subsection{Indirect estimation of load capacity of piles from CPT}

One of the possible methods of estimation of bearing capacity of pile is indirect, like engineering method, where data from CPT testing are used for calculation of soil parameters. Unit skin friction $f_{p}$ and end bearing carrying capacity of the pile $q_{b}$ should be estimated by using soil parameters. Commonly analyses with total parameters are used (total stress principle) for clays and silts, for sandy and gravelly soils there are used approaches which use effective stress theory. However, the second principle, which uses the effective stress, is useful and reliable for all types of soil, and not only for sand and gravel as well. In general, the method is described by (2) interpreted by Kulhawy [10]:

$f_{p}=C_{M} \cdot C_{K} \cdot K_{0} \cdot \sigma_{o r, v}{ }^{\prime} \cdot \tan \varphi^{\prime}$,

where: $C_{M} \quad$-interaction coefficient soil/pile material;

$C_{K} \quad$ - coefficient according to pile installation technology;

$K_{0} \quad$ - coefficient of horizontal stress (at rest);

$\sigma_{o r, v}{ }^{\prime}$ - effective vertical stress in soil;

$\varphi \quad-$ effective angle of friction.

Table 1: Modified terms for pile material type $\left(C_{M}\right)$ and installation effects $\left(C_{K}\right)$ after Kulhawy et al. in [8]

\begin{tabular}{|c|l|c|}
\hline \multirow{4}{*}{\begin{tabular}{|l|} 
Interaction coefficient $C_{M}$ \\
\cline { 2 - 2 }
\end{tabular}} & Soil / smooth steel & 0.6 \\
\cline { 2 - 3 } & Soil / rough steel - H profile & 0.7 \\
\cline { 2 - 3 } $\begin{array}{c}\text { Coefficient of pile installation } \\
\text { technology } \\
C_{k}\end{array}$ & Soil wooden pile & 0.8 \\
\cline { 2 - 3 } & Soil / smooth concrete pile (precast) & 0.9 \\
\cline { 2 - 3 } & Soil / rough concrete pile (bored, drilled shaft) & 1.0 \\
\cline { 2 - 3 } & Jetted piles (vibrofloated) & $0.5-0.6$ \\
\cline { 2 - 3 } & Driven or bored pile & $0.9-1.0$ \\
\cline { 2 - 3 } & Low-displacement driven piles & $1.0-1.1$ \\
\cline { 2 - 3 } & High-displacement driven piles & $1.1-1.2$ \\
\hline
\end{tabular}

End bearing capacity of single pile can be calculated from theoretical approach of limit plastic behaviour at undrained conditions of stress from (3):

$q_{b}=* N_{c} \cdot s_{u}$,

where: ${ }^{*} N_{c}=9.33-$ is for circular and square profile of piles; 
$s_{u}-$ is a representative undrained shear strength of soil layer below pile bottom of height of 1 diameter of pile, see Fig. 3., $z=L$ to $z=L+d$; [4].

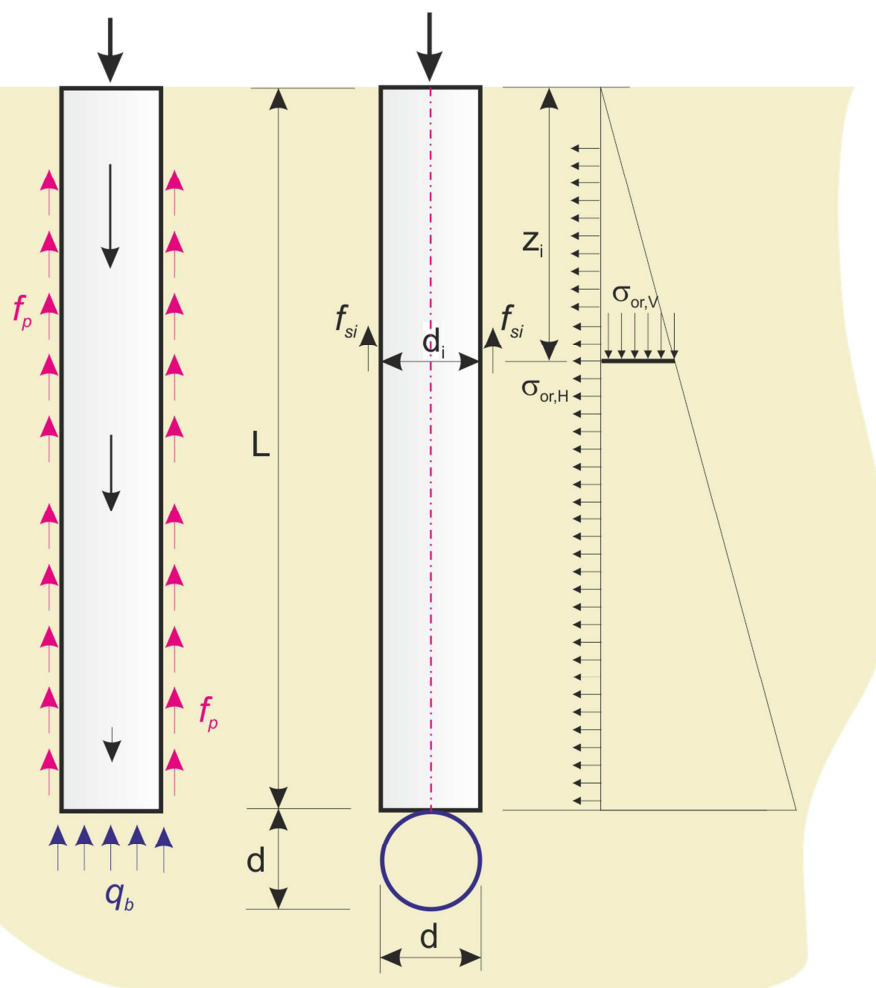

Fig. 2: Active zone for bearing capacity calculation.

\subsection{Indirect calculation of load capacity according to ultimate limit state}

Another indirect method to calculate load capacity (resistance) of single pile uses geotechnical parameter derived from CPT. Resistance of pile is calculated based on ultimate limit state conditions at pile bottom $R_{b d}$ and limit shaft friction $R_{f d}[6,11]$ :

$R_{u l s}=R_{b d}+R_{f d}=K_{1} \cdot A_{b} \cdot R_{d}+\sum \pi \cdot d_{i} \cdot h_{i} \cdot f_{s i}$

where: $K_{1}-$ is coefficient $\geq 1.0$ related to length of pile,

$R_{d}$ - end bearing resistance calculated by formula (5),

$f_{s i}$ - unit shaft friction according to formula (6),

$h_{i}$ - height of partial soil layer with average value of original horizontal stress $\sigma_{o r, h}$,

$z_{i}$ - distance to middle of layer from original surface, see Fig. 2.

$$
\begin{aligned}
& R_{d}=1.2 \cdot c_{d} \cdot N_{c}+\left(1+\sin \varphi_{d}\right) \cdot \gamma_{1} \cdot L \cdot N_{d}+0.7 \cdot \gamma_{2} \cdot \frac{d}{2} \cdot N_{b}, \\
& f_{s i}=K_{2} \cdot \sigma_{o r, v, i} \cdot \tan \left(\frac{\varphi_{d, i}}{\gamma_{r 1}}\right)+\frac{c_{d, i}}{\gamma_{r 2}} .
\end{aligned}
$$

here: $\quad K_{2} \quad-$ is coefficient of horizontal earth pressure at depth $z<10 \mathrm{~m} K_{2}=1$; at $z>10 \mathrm{~m} K_{2}=1.2$;

$L \quad$ - length of pile,

$\gamma_{1}, \gamma_{2}$ - unit weight of soil up and below pile bottom,

$\sigma_{o r, v, i}$ - original vertical stress in middle of partial soil layer,

$\gamma_{r 1}, \gamma_{r 2}-$ coefficients related to technology of pile. 


\subsection{Direct estimation of pile load capacity from CPT}

Empirical approach to assessing the piles load capacity in clay has been developed jointly between NGI, Oslo and BRE London [8]. One of these used correlations was presented for estimation of unit skin friction resistance of driven pile in clays related to cone resistance from CPT test $[4,8]$ :

$f_{p}=\frac{q_{c}-\sigma_{o r, v}}{10.5+13.3 \cdot \log Q_{c n}}$,

$q_{c}-$ is cone resistance $[\mathrm{kPa}]$,

$\sigma_{o r, v}$ - is vertical stress acting in the soil $[\mathrm{kPa}]$ and $Q_{c n}$ is normalized cone resistance according to eq. (8)

$Q_{c n}=\frac{\frac{q_{c}}{p_{a}}}{\left(\frac{\sigma_{o r, v}^{\prime}}{p_{a}}\right)^{0.5}}$,

$Q_{c n}$ - is normalized penetration resistance [-],

$p_{a}-$ is the constant of atmospheric pressure $[101.3 \mathrm{kPa}]$.

Bearing capacity of the pile base is provided similarly in the action zone of the pile, i.e. at a depth of $L$ to $L+d$ and is determined by the formula:

$q_{b}=\frac{q_{c}-\sigma_{o r, v}^{\prime}}{k_{2}}$,

where: $k_{2}=N_{k} / 9$ for piles acting in soft to stiff clays cone factor $N_{k}=15$, in weathered and disturbed claystones, very stiff claystones 25 to 35 , [10]. Direct values of $k_{2}$ can be derived in range 1.5 to 3.4 , [4]. The coefficient $k_{2}$ is in relation with cone factor $N_{k}$, which is a constant for specific soil type. $N_{k}$ factor can vary from 5 to 75 ; however, most values are in interval 10 to 30 and, further, most values are in the 15 to 20 range.

\section{Model locality for comparison study}

Model locality belongs to Danube neogenous basin, its north-eastern part, and it is located 12 $\mathrm{km}$ northwest from city Levice. Territory of this locality presents different geological and geomorphological features:

- Quaternary sediments are represented by fluvial and deluvial deposits thickness of up to 20 $\mathrm{m}$. Sediments of this upland area are represented by loess loams of polygenic origin to loess with thickness of $10 \mathrm{~m}$, mainly from Würm age.

- Neogenous sediments were formed during the Neogene Age and are related with different deposition conditions, particularly marine facies (bottom of the deep and shallow sea), and continental facies (freshwater lake and tropical forest).

Detailed geological situation is presented by the local map of locality on Figure 3. 


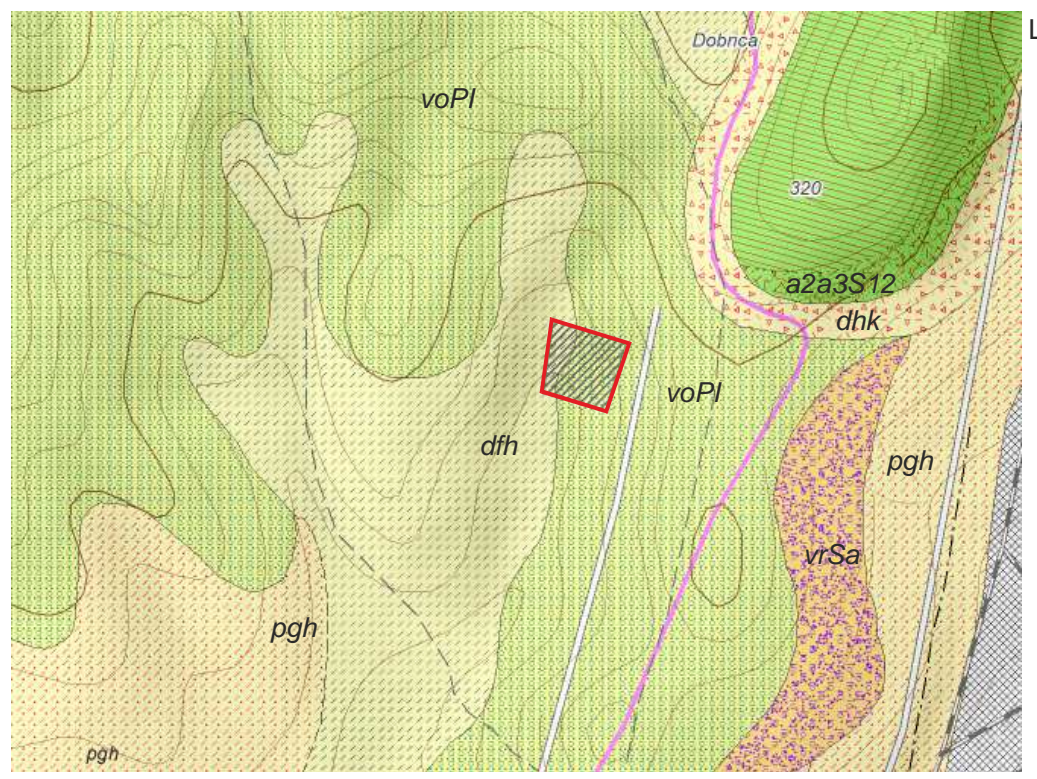

LEGEND:

Quaternary:

dfh - deluvial / fluvial sediments

dhk - deluvial sediments - clayey-sandy silts pgh - colluvial polygenetic debris

Neogene:
Pliocene

voPI - Volkovské strata - sands, gravels, gravels with fine soil

Miocene

vrSa - Vrábel'ské strata - sands, clays, sandstones, conglomerates, limestones

a2a3S12 - amphibolic pyroxenic breccias

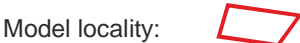

supposed geological border - - - -

geological border

Fig. 2: Simple geological map of model locality [12].

The total depth of CPT probe was designed to be $20 \mathrm{~m}$ at model locality, but due to capacity of the unit and geological conditions this depth was not reached. Location of the probes was $2 \mathrm{~m}$ in the distance from rotary core drilling boreholes.

\subsection{Methodology}

For direct and indirect calculation of load capacity of piles two CPT probes in clayey soil profile were selected. Every method uses cone factor $N_{k}$ in calculation steps, therefore simple methodology was used through correlation to undrained shear strength $s_{u}$.

The undrained shear strength $s_{u}$ is required for short-term load on saturated clayey and silty layers. Undrained shear strength $s_{u}$ is equal to total cohesion $c_{u}$, when total angle of friction leading to $0^{\circ}$. This parameter is used frequently for bearing capacity evaluation of cohesive soils. The classic approach at the evaluation of CPT tests can be $c_{u}$ derived directly from the cone resistance $q_{c}$ through formula:

$c_{u}=\frac{q_{c}-\sigma_{o r, v}}{N_{k}} ;$

$N_{k}$ - is the cone factor at undrained conditions. Based on theoretical approaches mentioned above, the value of cone factor was established by simple static approach, [14].

\subsection{Calculation steps}

A. First calculation was done from CPT cone resistance values $q_{c}$, used in eq. (8) for estimation of total cohesion of soil $c_{u}[15]$ :

$c_{u}=46.86 \cdot q_{c}-25.6$.

B. Cone factor $N_{k}$ was calculated from equation (10) by substitution $c_{u}$ by eq. (11). Normal probabilistic distribution function was used for statistical evaluation. From the seven penetration probes were determined $560 N_{k}$ values, later these numbers have been reduced to 527 values to meet the condition of similar geological environment, and the second phase of reduction to 509 values was according to rule $3 \sigma$.

C. Weighted average has been calculated from the values $N_{k}$, which were 24 after rounding to whole numbers.

D. All descriptive statistical parameters are presented in the Table 2.

There were plotted graphs, which help to indicate the correctness of procedure for data analysis. The first one was a histogram chart of frequency, from which the more obvious value of $N_{k}$ 
can be estimated, the second graph plotted dependence between the values of $N_{k}$ and the probability of occurrence.

Table 2: Comparison of descriptive statistical values of parameter $N_{k}$.

\begin{tabular}{|l|c|c|c|}
\hline \multicolumn{4}{|c|}{ Descriptive statistical values } \\
\hline No. & No reduced set & 1. reduced set & 2. reduced set \\
\hline Min. value & 560 & 527 & 509 \\
\hline Max. value & 22 & 22 & 22 \\
\hline Avg. & 235 & 35 & 29 \\
\hline Modus & 26.92 & 24.24 & 23.94 \\
\hline Dispersion & 23 & 23 & 23 \\
\hline Standard deviation & 250.64 & 5.93 & 3.41 \\
\hline Standard error & 15.83 & 2.43 & 1.85 \\
\hline Absolute error & 0.67 & 0.11 & 0.08 \\
\hline
\end{tabular}
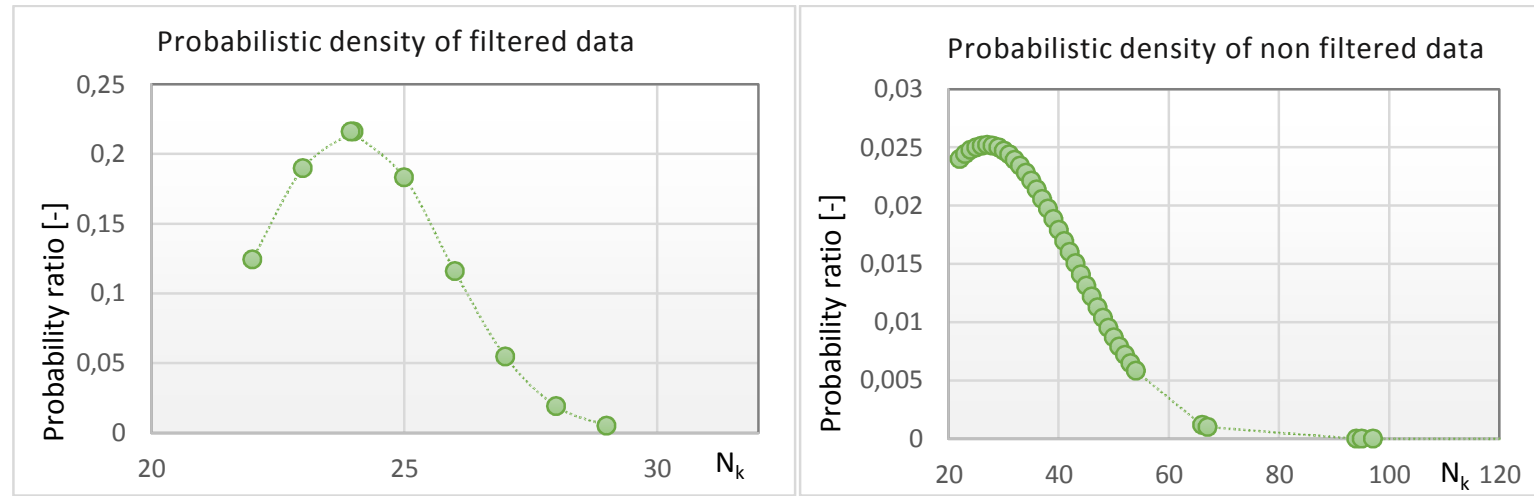

Fig. 3: Confidence interval of average value of $N_{k}$.

\section{Comparison of results of pile resistance estimation}

The bearing resistance of pile has been calculated following by determination of inputs data from seven CPT probes. It was used direct method of Powell [13], indirect methods of Kulhawy [10] and calculation according to ultimate limit state of pile $R_{u l s}[7,11]$. The results of calculations are summarized in the following Table 3.

Table 3: Comparison of calculated bearing capacity of piles from two selected CPT probes.

\begin{tabular}{|c|c|c|c|c|c|c|c|}
\hline & \multirow{2}{*}{ Depth [m] } & \multicolumn{3}{|c|}{ CPT-5 } & \multicolumn{3}{|c|}{ CPT-6 } \\
\hline & & Powell & Kulhawy & $\boldsymbol{R}_{u l s}$ & Powell & Kulhawy & $\boldsymbol{R}_{u l s}$ \\
\hline \multirow{8}{*}{ 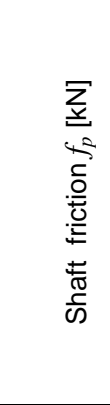 } & 1 & 90.7 & 11.7 & 58.5 & 64.0 & 12.4 & 55,5 \\
\hline & 2 & 174.1 & 29.2 & 61.1 & 107.4 & 31.1 & 63,3 \\
\hline & 3 & 161.1 & 47.5 & 71.8 & 176.1 & 46.8 & 78,2 \\
\hline & 4 & 166.1 & 65.9 & 83.3 & 372.6 & 55.6 & 205,8 \\
\hline & 5 & 192.7 & 82.1 & 93.3 & 269.9 & 77.6 & 128,5 \\
\hline & 6 & 215.2 & 98.0 & 105.8 & 234.9 & 96.4 & 108,8 \\
\hline & 7 & 258.0 & 111.6 & 121.4 & 238.3 & 113.5 & 118,6 \\
\hline & 8 & 257.1 & 129.0 & 131.0 & 311.5 & 123.6 & 141,2 \\
\hline \multicolumn{2}{|c|}{ Shaft resistance $[\mathrm{kN}]$} & 1515.1 & 575.0 & 726.2 & 1774.7 & 557.0 & 899.9 \\
\hline \multicolumn{2}{|c|}{ End bearing resistance [kN] } & 524.5 & 543.7 & 510.3 & 679.3 & 704.2 & 548.7 \\
\hline \multicolumn{2}{|c|}{ Total resistance $[\mathrm{kN}]$} & 2039.6 & 1118.7 & 1236.5 & 2454.0 & 1261.3 & 1448.6 \\
\hline
\end{tabular}


Bored piles design were selected for comparison study and was considered the material coefficient $c_{K}=0.9$, interaction coefficient soil/pile $c_{M}=0.9$. Direct method of calculation of pile capacity does not need any technology coefficient and it is independent from pile material type. Model pile was length of $8 \mathrm{~m}$ with diameter of $600 \mathrm{~mm}$.

\section{Conclusions}

Based on the carried out analysis of load capacity of piles according to different approaches from CPT probes results it should be stated that big differences are in shaft resistance estimation (more than $100 \%$ ). End bearing capacity through different approaches provided similar results for design of pile foundations. It cannot be stated which approach is the most precise, this can be known when static load test is completed, [16]. Another advantage of using CPT testing is the receiving of more certainty in geological input data and this can be also convenient for reducing costs for static load tests of realized piles [8].

The CPT, CPTu tests, in addition to sufficient accuracy of obtained data for pile evaluation, provides also others valuable information and geotechnical parameters, e.g. liquefaction potential, sensitivity, consolidation, permeability, $[7,14,17]$.

\section{References}

[1] BULKO, R. - DRUSA, M. - VLČEK, J. - MEČÁR, M.: CPT Profiling and Laboratory Data Correlations for Deriving of Selected Geotechnical Parameter. In: Civil and Environmental Engineering, Vol. 11, Issue 2/2015, p. 152 - 157, DOI: 10.1515/cee-2015-0020.

[2] MAYNE, P. W.: In-Situ Test Calibrations for Evaluating Soil Parameters, Overview Paper, Characterization and Engineering Properties of Natural Soils II (Proceedings of Singapore Workshop). Taylor \& Francis Group, London, United Kingdom, 2006.

[3] LUNNE, T. - ROBERTSON, P. K. - POWELL, J. J. M.: Cone Penetration Testing in Geotechnical Practice. Blackie Academic, EF Spon/Routledge Publishers, New York, N.Y., 1997, 312 p.

[4] BOWLES, J. E.: Foundation Analysis and Design. 5th edition, The McGraw-Hill Companies, Inc. 1997, ISBN 0-07-118844-4.

[5] FELLENIUS, B. H., - ESLAMI, A.: Soil profile interpreted from CPTu data. In: Year 2000 Geotechnics - Geotechnical Engineering Conference, Asian Institute of Technology, Bangkok, Thailand, November 27 - 30, 2000, 18 p.

[6] DRUSA, M. - MORAVČíK, M.: Foundation Structures. Edis, Žilina, 2008, 118 p., ISBN 978-80554-0068-6.

[7] DRUSA, M.: Improvement in Evaluation of Neogenous Soils by CPT Testing. In: Proceedings of SGEM 2012, Vol II., p. 151 - 158, ISSN 1314-2704, DOI: 10.5593/sgem2012.

[8] MAYNE, P. W.: NCHRP SYNTHESIS 368: Cone Penetration Testing: A Synthesis of Highway Practice. Transportation Research Board, Washington, D.C. 2007, ISSN 0547-5570.

[9] DENICOLA, A. - RANDOLPH, M. F.: Tensile and Compressive Shaft Capacity of Piles in Sand. In: Journal of Geotechnical Engineering, Vol. 119, No. 12/1993, p. 1952 - 1973.

[10] KULHAWY, F. H. - MAYNE, P. W.: Manual on Estimating Soil Properties for Foundation Design. Report EPRI EL-6800, Electric Power Research Institute, Palo Alto, California, 1990, 306 p.

[11] MASOPUST J.: Special foundation engineering (in Czech). CERM Brno 2004, ISBN 80-2142770-1.

[12] http://apl.geology.sk/mapportal/, [access: 04/2016]

[13] POWELL, J. J. M. - LUNNE, T. - FRANK, R.: Semi-Empirical Design for Axial Pile Capacity in Clays. In: Proceedings of 15th International Conference on Soil Mechanics and Geotechnical Engineering, Vol. 2, (Istanbul, Turkey). Balkema, Rotterdam, the Netherlands, 2001, p. 991 - 994.

[14] ROBERTSON, P. K.: Soil Classification Using the Cone Penetration Test. In: Canadian Geotechnical Journal, Vol. 27, No. 1/1990, p. 151 - 158.

[15] MATYS, M. et al.: In-situ testing of soils (in Slovak). Bratislava, ALFA, 1990, 304 p., ISBN 80-0500647-0.

[16] DRUSA, M. - VLCEK, J.: Numerical approach to pile load test using 3D finite element method. In: Communications - scientific letters of the University of Žilina. Vol. 16, Issue 4/2014 p. 94 - 97, ISSN 1325-4205. 
[17] VLČEK, J. - ĎUREKOVÁ, D. - ZGÚTOVÁ, K.: Evaluation of dynamic methods for earthwork assessment. In: Civil and Environmental Engineering. Vol. 11, Issue 1/2015, p. 38 - 44, ISSN 1336-5835, DOI: 10.1515/cee-2015-0005. 